\title{
Evaluation of novel pyrimidine derivatives as a new class of mushroom tyrosinase inhibitor
}

This article was published in the following Dove Press journal:

Drug Design, Development and Therapy

\author{
S Shohreh Mirmortazavi ${ }^{1}$ \\ Mahdieh Farvandi' \\ Hossein Ghafouri' \\ Asadollah Mohammadi ${ }^{2}$ \\ Mostafa Shourian' \\ 'Department of Biology, Faculty of \\ Sciences, University of Guilan, Rasht, \\ Iran; ${ }^{2}$ Department of Chemistry, Faculty \\ of Sciences, University of Guilan, Rasht, \\ Iran
}

Background and aim: Tyrosinase (EC 1.14.18.1) is responsible for enzymatic browning in fruits and vegetables. Its inhibitors may be applied to efficiently treat hyperpigmentation and are widely used in pharmaceutical and cosmetic products, food supplements and insecticides. Previous studies have shown that heterocyclic compounds with an amino group can inhibit tyrosinase activity. The present study aims to evaluate the inhibitory effect of some novel 2,6-diamino-4-chloropyrimidine derivatives (1a-e) and 2,4,6-triaminopyrimidine $(2 \mathrm{a}-\mathrm{e})$ including bioactive aniline moiety on the activity of the mushroom tyrosinase.

Methods: In practice, the azo salt was initially synthesized from aniline derivatives and combined subsequently with the 2,4,6-triaminopyrimidine and 2,6-diamino-4 chloropyrimidine followed by crystallization. The structures of resulting compounds were confirmed by FT-IR, ${ }^{13} \mathrm{C}$ NMR, and ${ }^{1} \mathrm{H}$ NMR. The derivatives $(0-100 \mu \mathrm{M})$ were evaluated for their inhibitory effect on tyrosinase activity using 1-3,4-dihydroxyphenylalanine (1-DOPA) as substrate.

Results: All compounds showed inhibitory effects against the activity of the enzyme. About $23.72-55.08 \%$ inhibition was observed in the presence of $30 \mu \mathrm{M}$ of each compound. The $\mathrm{IC}_{50}$ values of the synthesized compounds were measured, and their inhibition properties were also visualized by zymography. Based on the results, the compounds 1a-e and 2a-e showed moderate inhibitory activities. Notably, pyrimidine derivatives $1 \mathrm{a}\left(\mathrm{IC}_{50}=24.68\right)$ and $1 \mathrm{~d}\left(\mathrm{IC}_{50}=24.45\right)$ also exhibited similar inhibitory activities when compared with the positive control, kojic acid $\left(\mathrm{IC}_{50}=25.24 \mu \mathrm{M}\right)$. Kinetic studies indicated that the type of inhibition was noncompetitive.

Conclusion: All results suggest that pyrimidine derivatives, especially $1 \mathrm{~d}$ and $1 \mathrm{a}$, can be considered as safe and efficient tyrosinase inhibitors.

Keywords: mushroom tyrosinase, inhibitor, pyrimidine derivatives, noncompetitive inhibition

\section{Introduction}

Tyrosinase is a copper-dependent enzyme from the oxidoreductase family considered as the rate-limiting enzyme in the melanin production pathway. Melanin is a dark brown to black pigment that effectively absorbs light. It is found in plants and fungi as well as in hair, skin, and iris of the eye in human and animals. ${ }^{1,2}$ Tyrosinase is one of the multifunctional enzymes that catalyze two different reactions resulting from the binding of dioxygen to two copper atoms in the strongly conserved active center: the hydroxylation of monophenols (tyrosine) to o-diphenols (monophenolase activity) and the oxidation of o-diphenols to o-quinones (diphenolase activity). The process ultimately leads to the production of melanin through several reactions from o-quinones. ${ }^{2,3}$ This type of
Correspondence: Hossein Ghafouri Department of Biology, Faculty of Sciences, University of Guilan, Namjoo Ave, P.O. Box 41335-1914, Rasht, Iran $\mathrm{Tel} / \mathrm{Fax}+98 \quad$ I33 3333647

Email h.ghafoori@guilan.ac.ir 
tyrosinase activity is due to four possible oxidation states (deoxy-, oxy-, met- and deact-tyrosinase). At the met state, both copper atoms present in the active site are in $\mathrm{Cu}$ (II) state. In the case of the deoxy state, copper atoms in $\mathrm{Cu}$ (I) can be attached to molecular oxygen. At the oxy state, the molecular oxygen in peroxy conformation is surrounded by both copper atoms in a $\mathrm{Cu}$ (II) state, in which case it can be linked to phenols and catechols, as substrate, converting them into ortho-quinones by different oxidative cycles. The deact state is an inactivated form of tyrosinase with one of the copper atoms in the $\mathrm{Cu}(0)$ state and the other in the $\mathrm{Cu}$ (II) state. ${ }^{3}$ Given this background, while pigmentation under normal conditions protects skin against harmful UV injury, melanin increment due to the tyrosinase hyperactivity can give rise to hyperpigmentation disorders, which is followed by freckles, wrinkles, age spots, skin irritation, postinflammatory hyperpigmentation, melanoderma and melasma in extreme cases that are particularly common among women. ${ }^{4,5}$ Tyrosinase is regarded as a key agent in the risk of malignant melanoma cancer and might play a significant role in neuromelanin production responsible for the neurodegeneration associated with Parkinson's and Huntington's diseases. ${ }^{6,7}$ Tyrosinase has also been confirmed to be one of the most important causes of browning in vegetables and fruits during post-harvest, handling, and storage, leading to quick degradation. ${ }^{8,9}$ Finally, tyrosinase has a different biochemical process in insects, including wound healing, sclerotization, melanin synthesis, and defensive encapsulation. ${ }^{10,11}$ Therefore, the production of useful and safe inhibitors of tyrosinase as insecticides and skin lightening agents is important for the agricultural, cosmetic and medical industries. While there have been many efforts to discover effective inhibitors, only a few compounds have been used commercially for therapeutic and cosmetic uses; these include kojic acid, tropolone, arbutin and 1-phenyl2-thiourea (PTU). ${ }^{12,13}$ Tyrosinase can oxidize several aromatic amines and o-aminophenols as substrates, which are analogs of monophenols and o-diphenols, respectively. ${ }^{13,14}$ 4-Aminophenylalanine, 4-aminotoluene, 4-aminoacetanilide, and several o-aminophenolic derivatives of benzoic acid served as substrates for the enzyme. ${ }^{14}$ Because of the widespread presence of a pyrimidine ring in biological and organic compounds such as nucleic bases, vitamins, enzymes, chlorophyll, hemoglobin, and hormones, and, moreover, the broad spectrum of pharmaceutical properties subsequently has attracted much attention in drug industries. ${ }^{15,16}$ Pyrimidine and its derivatives with an active heterocyclic structure having two nitrogen atoms in the ring are highly regarded as interesting bioactive compounds in medicinal chemistry. These heterocyclic compounds have anticancer, antiviral, antiinflammatory, antibacterial, and antiparkinson properties. ${ }^{15}$ Considering that several aromatic amines can play a role as tyrosinase substrates, and the fact that amines and anilines are its inhibitors, we decided to synthesize new derivatives based on pyrimidine and aniline derivatives. ${ }^{14,17}$ In this study, for the first time, we synthesized a series of novel azo-pyrimidine dyes and evaluated the inhibitory activities of these low-cost and easy-to-prepare compounds against mushroom tyrosinase based on dopaquinone production by an enzyme assay with L-dopa as substrate. The $\mathrm{IC}_{50}$ was obtained and compared with kojic acid as positive control. Also, zymography was used to show the inhibitory effects of these compounds on tyrosinase activity. The kinetic analysis revealed the $\mathrm{Ki}$ value and inhibition mechanism, and finally, the docking study of these compounds was performed by the auto dock software and Swiss dock web server.

\section{Materials and equipment}

All chemicals and reagents used in this study were purchased from Sigma-Aldrich Co., St Louis, MO, USA and Merck Chemical companies and used without further purification. Silica gel thin layer chromatography (TLC) using n-hexane and ethyl acetate as mobile phase was used to monitor the progress of reactions. The solutions were prepared using distilled water. Melting points $\left({ }^{\circ} \mathrm{C}\right)$ of the synthesized compounds were recorded on Electrothermal IA9000 equipment (ColeParmer, Stone, UK) and are uncorrected. The UV-visible absorption spectra were recorded using a Pharmacia Biotech Spectrophotometer in the range of $200-800 \mathrm{~nm}$. Fourier transform infrared (FT-IR) spectra were recorded on a Shimadzu 8400 FT-IR spectrophotometer (Shimadzu, Kyoto, Japan). ${ }^{1} \mathrm{H}$ NMR and ${ }^{13} \mathrm{C}$ NMR spectra were obtained on an FTNMR (400 MHz) Bruker apparatus (Bruker AXS Inc., Madison, WI, USA), the chemical shifts were expressed in $\delta$ ppm using TMS as an internal standard and $J$ values in $\mathrm{Hz}$.

\section{Synthesis of pyrimidine-based azo dyes (la-e and 2a-e)}

Pyrimidine-based azo dyes (1a-e and 2a-e) were synthesized in high yield via diazotization and coupling reactions as shown in Figure 1. One mmol of diazonium salts from donor- and acceptor-substituted anilines was prepared according to a method previously described. ${ }^{18}$ To $1 \mathrm{mmol}$ of solution containing coupling reagent (2,4,6-triaminopyrimidine or 2,6-diamino-4-chloropyrimidine) was added dropwise from diazonium salt from 


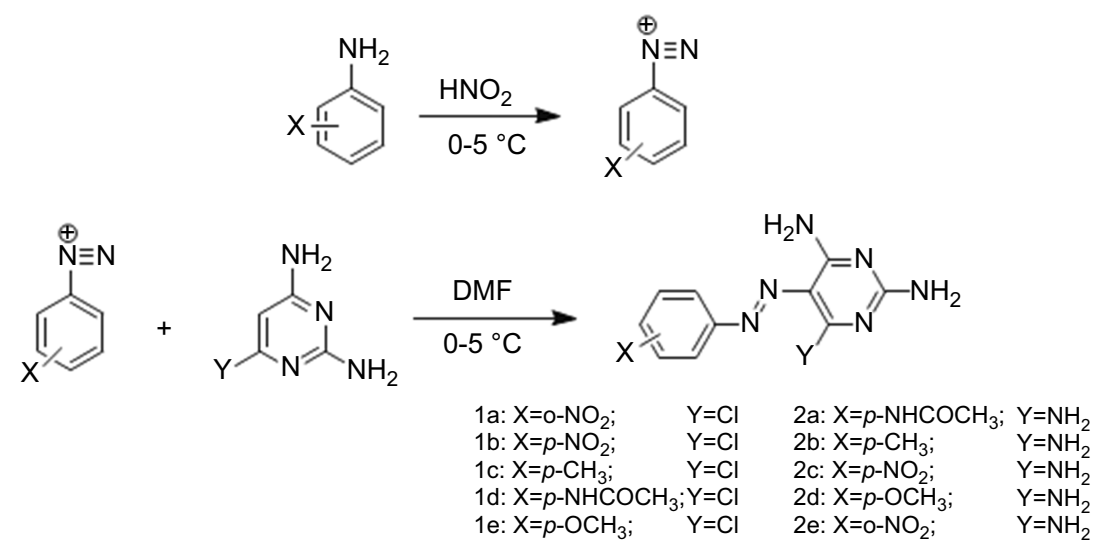

Figure I Synthesis of diazonium salts from aniline derivatives. Reagents and conditions: aniline derivatives, $\mathrm{H}_{2} \mathrm{SO}_{4}, \mathrm{NaNO}_{2}$, stirring at $0-5^{\circ} \mathrm{C}$. Synthesis of pyrimidine-based azo dyes ( $\mathrm{Y}=\mathrm{Cl}$ : 2, 6-diamino-4-chloropyrimidine) $\mathrm{Y}=\mathrm{NH} 2$ : 2, 4, 6-triaminopyrimidine. Reagents and conditions: Diazonium salts from aniline derivatives, TAP or DATP, DMF, stirring in $0-5^{\circ} \mathrm{C}$.

the previous step over 30 min with stirring at $0-5^{\circ} \mathrm{C}$. The stoichiometry ratio was $1: 1$. The $\mathrm{pH}$ of the solution was slowly adjusted to 7 with $\mathrm{HCl}(0.5 \mathrm{M})$. The reaction was continued by addition of $20 \mathrm{ml}$ distilled water to precipitate. The precipitate was then filtered and washed with water (three times). The crude products were isolated by recrystallization from dimethylformamide $(\mathrm{DMF}) / \mathrm{H}_{2} \mathrm{O}$ at $80^{\circ} \mathrm{C}$. Structures of the obtained azo dyes were confirmed by FT-IR and NMR $\left({ }^{1} \mathrm{H}\right.$ and $\left.{ }^{13} \mathrm{C}\right)$ spectroscopy.

Compound la (6-chloro-5-((2-nitrophenyl) diazenyl) pyrimidine-2,4-diamine)

Red solid; yield $79 \%$; melting point (MP) $301-303^{\circ} \mathrm{C}$. FTIR $\left(\mathrm{KBr}, \mathrm{cm}^{-1}\right): 3,467(\mathrm{NH}), 3,308(\mathrm{NH}), 3,138(\mathrm{NH})$, 1,636 $(\mathrm{C}=\mathrm{N}), 1,565\left(\mathrm{NO}_{2}\right), 1,509(\mathrm{~N}=\mathrm{N}) .{ }^{1} \mathrm{H}$ NMR $(400$ MHz, DMSO-d $6,298 \mathrm{~K}), \delta$ (ppm): 7.58-7.62 (m, 2H), 7.76 (s, 1H, NH), 7.79-7.85 (m, 2H, Ar-H), 8.05 (d, 1H, $J=8.0 \mathrm{~Hz}, \mathrm{Ar}-\mathrm{H}), 8.42$ (s, 1H, NH), 9.22 (s, 1H, NH). ${ }^{13} \mathrm{C}$ NMR (DMSO-d $\left.{ }_{6}\right), \delta$ (ppm): 118.1, 120.4, 125.1, $129.7,134.2,144.7,146.1,156.2,161.9,166.1$.

Compound Ib (6-chloro-5-((4-nitrophenyl) diazenyl) pyrimidine-2,4-diamine)

Orange solid; yield $82 \%$; MP $305-307^{\circ} \mathrm{C}$. FT-IR $\left(\mathrm{KBr}, \mathrm{cm}^{-1}\right)$ : 3,502 (NH), 3,327 (NH), 3,186 (NH), 1,632 $\left(\mathrm{NO}_{2}\right), 1,569(\mathrm{C}=\mathrm{N}), 1,514(\mathrm{~N}=\mathrm{N}) .{ }^{1} \mathrm{H}$ NMR $(400 \mathrm{MHz}$, DMSO-d $\left._{6}, 298 \mathrm{~K}\right), \delta(\mathrm{ppm}): 7.55$ (s, 1H, NH), $7.73(\mathrm{~s}, 1 \mathrm{H}$, NH), 7.90 (d, 2H, $J=8.8 \mathrm{~Hz}, \mathrm{Ar}-\mathrm{H}), 8.35$ (d, 2H, $J=7.6 \mathrm{~Hz}$, $\mathrm{Ar}-\mathrm{H}), 8.39(\mathrm{~s}, 1 \mathrm{H}, \mathrm{NH}), 9.41(\mathrm{~s}, 1 \mathrm{H}, \mathrm{NH}) .{ }^{13} \mathrm{C} \mathrm{NMR}$ $\left(\right.$ DMSO-d $\left._{6}\right), \delta$ (ppm): 120.1, 122.5, 125.4, 147.0, 156.4, $161.8,162.8,166.2$.
Compound Ic (6-chloro-5-(p-tolyldiazenyl) pyrimidine-2,4-diamine)

Light brown solid; yield $84 \%$; MP $234-236^{\circ} \mathrm{C}$. FT-IR $\left(\mathrm{KBr}, \mathrm{cm}^{-1}\right)$ : 3,385 (NH), 3,312 (NH), 3,205 (NH), 3,028 $(=\mathrm{CH}), 2,919(\mathrm{CH}), 1,643 \quad(\mathrm{C}=\mathrm{C}), 1,601 \quad(\mathrm{C}=\mathrm{N}), 1,551$ $(\mathrm{N}=\mathrm{N}) .{ }^{1} \mathrm{H}$ NMR $\left(400 \mathrm{MHz}, \mathrm{DMSO}_{6}, 298 \mathrm{~K}\right), \delta$ (ppm): 2.38 (s, 3H, $\left.\mathrm{CH}_{3}\right), 7.29(\mathrm{~s}, 1 \mathrm{H}, \mathrm{NH}), 7.33(\mathrm{~d}, 2 \mathrm{H}$, $J=8.0 \mathrm{~Hz}, \operatorname{Ar}-\mathrm{H}), 7.51$ (s, 1H, NH), 7.71 (d, 2H, $J=8.4 \mathrm{~Hz}$, Ar-H), 8.08 (s, 1H, NH), $9.28(\mathrm{~s}, 1 \mathrm{H}, \mathrm{NH}) .{ }^{13} \mathrm{C}$ NMR $\left(\right.$ DMSO- $\left._{6}\right), \delta$ (ppm): 20.4, 118.4, 121.9, 130.3, 139.7, $150.8,156.5,161.5,164.6$.

\section{Compound Id (N-(4-((2, 4-diamino-}

6-chloropyrimidin-5-yl) diazenyl) phenyl) acetamide) Dark red solid; yield $74 \%$; MP $286-288^{\circ} \mathrm{C}$. FT-IR $\left(\mathrm{KBr}, \mathrm{cm}^{-1}\right): 3,425(\mathrm{NH}), 3,390(\mathrm{NH}), 3,127(\mathrm{NH}), 1,691$ $(\mathrm{C}=\mathrm{O}), 1,658(\mathrm{C}=\mathrm{C}), 1,598(\mathrm{C}=\mathrm{N}), 1,502(\mathrm{~N}=\mathrm{N}) .{ }^{1} \mathrm{H}$ NMR

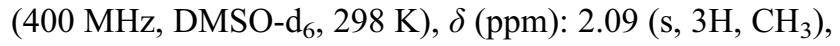
7.24 (s, 1H, NH), 7.34 (s, 1H, NH), 7.75 (m, 4H, Ar-H), $8.05(\mathrm{~s}, 1 \mathrm{H}, \mathrm{NH}), 9.27$ (s, 2H, NH), $10.19(\mathrm{~s}, 1 \mathrm{H}, \mathrm{NH})$. ${ }^{13} \mathrm{C}$ NMR (DMSO-d $\mathrm{d}_{6}$ ), $\delta$ (ppm): 24.5, 118.9, 122.7, 141.0, 148.3, 156.5, 161.4, 162.8, 164.3, 169.0.

\section{Compound le (6-chloro-5-((4-methoxyphenyl) diazenyl) pyrimidine-2,4-diamine)}

Dark red solid; yield $72 \%$; MP $270-272^{\circ} \mathrm{C}$. FT-IR $\left(\mathrm{KBr}, \mathrm{cm}^{-1}\right)$ : 3,366 (NH), 3,313 (NH), 3,201 (NH), 3,002 $(=\mathrm{CH}), 2,907(\mathrm{CH}), 1,648(\mathrm{C}=\mathrm{C}), 1,602(\mathrm{C}=\mathrm{N}), 1,550$ $(\mathrm{N}=\mathrm{N}) .{ }^{1} \mathrm{H}$ NMR $\left(400 \mathrm{MHz}, \mathrm{DMSO}_{6}, 298 \mathrm{~K}\right), \delta$ (ppm): 3.35 (s, $\left.3 \mathrm{H}, \mathrm{CH}_{3}\right), 7.0$ (s, 1H, NH), $7.08(\mathrm{~d}, 2 \mathrm{H}$, $J=8.8 \mathrm{~Hz}, \mathrm{Ar}-\mathrm{H}), 7.23$ (s, 1H, NH), 7.79 (d, 2H, $J=8.8$ $\mathrm{Hz}, \mathrm{Ar}-\mathrm{H}), 8.01$ (s, 1H, NH), 9.23 (s, 1H, NH). ${ }^{13} \mathrm{C}$ NMR 
$\left(\right.$ DMSO-d $\left._{6}\right), \delta$ (ppm): 39.4, 107.9, 114.6, 118.2, 123.4, $147.1,157.4,158.2,160.0$

Compound 2a N-(4-((2,4,6-triaminopyrimidin-5-yl) diazenyl) phenyl) acetamide

Red solid; yield $75 \%$; MP $284-286^{\circ} \mathrm{C}$. FT-IR $\left(\mathrm{KBr}, \mathrm{cm}^{-1}\right)$ : 3,389 (NH), 3,174 (NH), 2,960 $(=\mathrm{CH}), 2,929(\mathrm{CH}), 1,650$ $(\mathrm{C}=\mathrm{O}), 1,605(\mathrm{C}=\mathrm{N}), 1,501(\mathrm{~N}=\mathrm{N}) .{ }^{1} \mathrm{H}$ NMR $(400 \mathrm{MHz}$, DMSO-d $\left._{6}, 298 \mathrm{~K}\right), \delta$ (ppm): 2.09 (s, 3H, $\left.\mathrm{CH}_{3}\right), 7.06$ (s, 2H, NH), 7.61 (s, 2H, NH), 7.67 (d, 2H, J=8.0 Hz, Ar-H), 7.85 (d, 2H, $J=8.0 \mathrm{~Hz}, \mathrm{Ar}-\mathrm{H}), 8.66$ (s, 2H, NH), 10.10 (s, $1 \mathrm{H}, \mathrm{NH}) .{ }^{13} \mathrm{C}$ NMR (DMSO-d 6 ), $\delta$ (ppm): 24.5, 108.2, 119.6, 122.1, 122.4, 139.9, 148.5, 168.9.

\section{Compound 2b (5-p-tolyldiazenyl)} pyrimidine-2,4,6-triamine

Orange solid; yield $83 \%$; MP $250-252^{\circ} \mathrm{C}$. FT-IR $\left(\mathrm{KBr}, \mathrm{cm}^{-1}\right): 3,428(\mathrm{NH}), 3,338(\mathrm{NH}), 3,150(\mathrm{NH}), 2,958$ $(=\mathrm{CH}), 2,925(\mathrm{CH}), \quad 1,660(\mathrm{C}=\mathrm{C}), 1,599(\mathrm{C}=\mathrm{N}), 1,501$ $(\mathrm{N}=\mathrm{N}) .{ }^{1} \mathrm{H}$ NMR $\left(400 \mathrm{MHz}, \mathrm{DMSO}_{-} \mathrm{d}_{6}, 298 \mathrm{~K}\right), \delta(\mathrm{ppm})$ : 2.35 (s, 3H, $\left.\mathrm{CH}_{3}\right), 6.45$ (s, 2H, NH), 7.14 (s, 2H, NH), 7.23 (d, 2H, $J=7.6 \mathrm{~Hz}, \mathrm{Ar}-\mathrm{H}), 7.70$ (d, 2H, $J=6.8 \mathrm{~Hz}, \mathrm{Ar}-\mathrm{H}), 7.97$ (s, 2H, NH). ${ }^{13} \mathrm{C}$ NMR (DMSO-d $), \delta$ (ppm): 21.24, 109.9, 121.4, 129.9, 137.2, 151.3, 162.9, 162.9, 163.

\section{Compound 2c (5-((4-nitrophenyl) diazenyl)} pyrimidine-2,4,6-triamine)

Orange solid; yield $85 \%$; MP $307-309^{\circ} \mathrm{C}$. FT-IR $\left(\mathrm{KBr}, \mathrm{cm}^{-1}\right): 3,428(\mathrm{NH}), 3,316(\mathrm{NH}), 3,110(\mathrm{NH}), 1,695$ $\left(\mathrm{NO}_{2}\right), 1,508(\mathrm{~N}=\mathrm{N}) .{ }^{1} \mathrm{H}$ NMR $\left(400 \mathrm{MHz}, \mathrm{DMSO}_{-} \mathrm{d}_{6}, 298\right.$ $\mathrm{K}), \delta(\mathrm{ppm}): 7.36(\mathrm{~s}, 2 \mathrm{H}, \mathrm{NH}), 7.97(\mathrm{~s}, 2 \mathrm{H}, \mathrm{NH}), 8.12(\mathrm{~d}$, $2 \mathrm{H}, J=8.8 \mathrm{~Hz}, \mathrm{Ar}-\mathrm{H}), 8.27$ (d, 2H, $J=9.2 \mathrm{~Hz}, \mathrm{Ar}-\mathrm{H}), 9.05$ (s, 2H, NH). ${ }^{13} \mathrm{C}$ NMR (DMSO-d 6 ), $\delta$ (ppm): 122.3, 124.1, 125.2, 145.9, 157.4, 161.3, 162.8 .

\section{Compound 2d (5-((4-methoxyphenyl) diazenyl) pyrimidine-2,4,6-triamine)}

Yellow solid; yield $73 \%$; MP $\quad 278-280^{\circ} \mathrm{C}$. FT-IR $\left(\mathrm{KBr}, \mathrm{cm}^{-1}\right)$ : 3,463 (NH), 3,379 (NH), 3,280 (NH), 3,134 (NH), 1,503 (N=N). ${ }^{1} \mathrm{H}$ NMR (400 MHz, DMSO-d 6 , $\left.298 \mathrm{~K}\right)$, $\delta$ (ppm): 3.82 (s, 3H, $\mathrm{CH}_{3}$ ), 7.01 (d, $\left.2 \mathrm{H}, J=9.2 \mathrm{~Hz}, \mathrm{Ar}-\mathrm{H}\right)$, 7.05 (s, 2H, NH), 7.60 (s, 2H, NH), 7.88 (d, 2H, J=8.8 Hz, $\mathrm{Ar}-\mathrm{H}), 8.65$ (s, 2H, NH). ${ }^{13} \mathrm{C}$ NMR (DMSO-d ${ }_{6}$ ), $\delta$ (ppm): 39.4, 118.8, 123.1, 146.9, 156.5, 161.3, 164.1, 165.9.

\section{Compound 2e (5-((2-nitrophenyl) diazenyl)} pyrimidine-2,4,6-triamine)

Orange solid; yield $74 \%$; MP $322-324^{\circ} \mathrm{C}$. FT-IR $\left(\mathrm{KBr}, \mathrm{cm}^{-1}\right)$ : 3,398 (NH), 3,324 (NH), 3,170 (NH), 3,069 $(=\mathrm{CH}), 2,962-2,930(\mathrm{CH}), 1,666(\mathrm{C}=\mathrm{C}), 1,632\left(\mathrm{NO}_{2}\right)$,
1,513 (N=N). ${ }^{1} \mathrm{H}$ NMR (400 MHz, DMSO-d $\left.{ }_{6}, 298 \mathrm{~K}\right), \delta$ (ppm): 7.27 (s, 2H, NH), 7.46 (t, 1H, J=7.6, Ar-H), 7.71 (t, $1 \mathrm{H}, J=7.6 \mathrm{~Hz}, \mathrm{Ar}-\mathrm{H}), 7.95$ (s, 2H, NH), 7.97 (d, 1H, $J=8.0$ $\mathrm{Hz}, \operatorname{Ar}-\mathrm{H}), 8.28$ (d, 1H, J=8.4 Hz, Ar-H), 9.39 (s, 2H, NH). ${ }^{13} \mathrm{C}$ NMR (DMSO-d ${ }_{6}$ ), $\delta$ (ppm): 111.3, 118.4, 121.3, 123.8, 124.7, 127.6, 133.8, 145.1, 145.7.

\section{Mushroom tyrosinase inhibition assay $\left(\mathrm{IC}_{50}\right)$}

Tyrosinase was assayed in the presence of synthesized products using a previously described method with some modification. ${ }^{6}$ Briefly, reaction mixtures (total volume of $100 \mu \mathrm{L}$ ) with $70 \mu \mathrm{L}$ of phosphate buffer ( $\mathrm{pH} 6.8,100 \mathrm{mM}$ ) and $0,10,30,60,100 \mu \mathrm{M}$ synthesized compounds dissolved in DMSO (final concentration 7\% v/v) were firstly prepared. This was followed by the addition of $3 \mu \mathrm{L}$ mushroom tyrosinase $(0.0003 \mathrm{mg} / \mathrm{mL})$, mixing well and preincubation for $5 \mathrm{~min}$ at $37^{\circ} \mathrm{C}$. The final concentration of DMSO $(7 \% \mathrm{v} / \mathrm{v})$ did not interfere with the enzyme activity. Twenty $\mu \mathrm{L}$ of L-DOPA $(10 \mathrm{mM})$ were then added as the substrate and incubated for $30 \mathrm{~min}$ at $37^{\circ} \mathrm{C}$. Subsequently, the mixed solution was placed in a 96-well plate, and the absorbance of dopachrome was measured at $490 \mathrm{~nm}$ by ELISA reader. The half maximal inhibitory concentration of each tested compound $\left(\mathrm{IC}_{50}\right)$ was determined by interpolation of the dose-response curves. All the experiments were carried out in triplicate for each compound, and concentration and values were expressed as the means of three experiments before further calculation. Kojic acid and phosphate buffer were used as a reference inhibitor and negative control, respectively. The percent inhibition of the enzyme reaction was calculated as follows:

Inhibition rate $(\%)=(B-S) / B \times 100$

where $\mathrm{B}$ and $\mathrm{S}$ are the absorbance values for the blank and sample, respectively.

\section{Determination of the inhibition type and the inhibition constants}

In order to obtain kinetic parameters, the activity of tyrosinase was measured at different concentrations of substrate $(0,0.1,0.3,0.75,1.25$ and $2 \mathrm{mM})$ in the absence and presence of $30 \mu \mathrm{M}$ concentration of inhibitors. The protocol was the same as discussed in mushroom tyrosinase inhibition assay. Using the value of enzyme activity obtained from the assay in different concentrations of the substrate and inhibitor, Michaelis-Menten and Lineweaver-Burk 
plots were obtained. $\mathrm{Km}$ and Vmax were calculated from the Lineweaver-Burk plot linear equation and the inhibition constants were determined by the secondary plots of 1 / Vmax versus the concentration of the inhibitor.

\section{Zymogram analysis}

The effects of synthetic compounds on tyrosinase activity were also visualized by native polyacrylamide gel electrophoresis (PAGE). ${ }^{19}$ Synthesized compounds with the enzyme and the appropriate amount of phosphate buffer $(\mathrm{pH} 6.8,100 \mathrm{mM}$ ) were pre-incubated for $10 \mathrm{~min}$ and resolved in $12 \%$ PAGE. Preparation of samples was carried out with a sample buffer without mercaptoethanol without heat, and the electrophoresis was performed at $4^{\circ} \mathrm{C}$. After electrophoresis, the gel was washed twice with phosphate buffer at room temperature. An appropriate amount of L-DOPA $(10 \mathrm{mM})$ was later added in fresh buffer. The brown color bands of the product appeared after enzymatic activity with gentle shaking at $37^{\circ} \mathrm{C}$ for $1 \mathrm{~h}$.

\section{Docking}

The interaction of compound 1d as a ligand with tyrosinase was evaluated by molecular docking. The PDB code of the enzyme from the RCSB Protein Data Bank (http://www.rcsb. org) was obtained as $2 \mathrm{Y} \mathrm{W} \mathrm{W}^{20}$ The REDUCE program were fixed missing hydrogen of the tyrosinase crystal structure. ${ }^{21}$ The blind molecular docking was performed by the AutoDock program. ${ }^{22}$ The necessary input files were prepared by MGLTools, and the exhaustiveness parameter was set to $1,000 .{ }^{23}$ The structure of the ligand was built and optimized by Hyper-Chem program version 8 using a semi-empirical method (PM3 force filed). ${ }^{24}$ The images were created using Chimera 1.13.1 based on binding modes and scored using their FullFitness and clustered. ${ }^{25}$ Also, the molecular interactions between $1 \mathrm{~d}$ and tyrosinase was predicted by SwissDock web service (http://www.swissdock.ch).

The images were created using Python Molecule Viewer (PMV) and the program LigPlot v.1.0, which generate schematic two-dimensional representations of protein-ligand complexes from the input PDB file. ${ }^{23,26}$

\section{Results}

\section{Chemical synthesis}

The novel bis azo dye compounds (1a-e) and (2a-e) were synthesized (Figure 1). The structures of the synthesized compounds were confirmed by FTIR, ${ }^{1} \mathrm{H}$ NMR and ${ }^{13} \mathrm{C}$ NMR spectroscopic data (Figure 2). Wave scan rang for obtaining $\lambda_{\max }$ of all compounds was between 200 and $800 \mathrm{~nm}$. Chemical properties of synthetic compounds are presented in Table 1.

\section{The inhibitory effects of synthetic compounds on the enzyme activity}

In this study, all compounds were evaluated for their inhibitory effect on tyrosinase activity according to the procedure mentioned in the materials and methods section, and kojic acid was used as the reference inhibitor. The results indicated that percent inhibition of all compounds at $30 \mu \mathrm{M}$ concentration ranged from $23.72 \%$ (for $1 \mathrm{~b}$ ) to $55.08 \%$ (for 1e) as compared to kojic acid as a positive control with $57.27 \%$ inhibition at $30 \mu \mathrm{M}$ (Figure 3). The half maximal inhibitory concentration $\left(\mathrm{IC}_{50}\right)$ of synthetic compounds on tyrosinase activity was determined from logarithmic concentration-inhibition curves (Figure 4). As shown in Table 2, compounds 1d and 1a revealed the most potent inhibitory effects on the mushroom tyrosinase activity with $\mathrm{IC}_{50}$ values of 24.45 and $24.69 \mu \mathrm{M}$, respectively. Therefore, it was found that our new compounds are more potent inhibitors of tyrosinase than the reference inhibitor, kojic acid $\left(\mathrm{IC}_{50}=25.24 \mu \mathrm{M}\right)$. In addition, based on the results, it was found that compound $2 \mathrm{~d}\left(\mathrm{IC}_{50}=43.80\right.$ $\mu \mathrm{M})$ exhibited the lowest inhibitory activity on mushroom tyrosinase among all synthetic compounds.

\section{Tyrosinase zymography}

The effects of synthetic compounds on tyrosinase activity were visualized by L-DOPA staining assay. Tyrosinase oxidation activity on the gel can be observed as a dark band to a lighter band after adding L-DOPA solution. Upon incubation with the synthetic compounds, the band intensity decreased for each compound as compared to the untreated control. This phenomenon suggests that all the compounds had an inhibition effect on tyrosinase. As shown in Figure 5, while the lightest bands corresponded to $1 \mathrm{~d}$ and 1a compounds, compound $2 \mathrm{~d}$ showed minimal inhibitory effect compared to the other compounds. These results confirm our findings from inhibitory activity measured by the spectrophotometric method.

\section{The type of tyrosinase inhibition by synthetic compounds}

The steady-state kinetic analysis of all compounds for inhibition of enzyme activity on different concentrations of L-DOPA ( 0.1 to $2 \mathrm{mM}$ ) was carried out to determine their inhibition type and inhibition constants (Table 2). Lines intersect on 


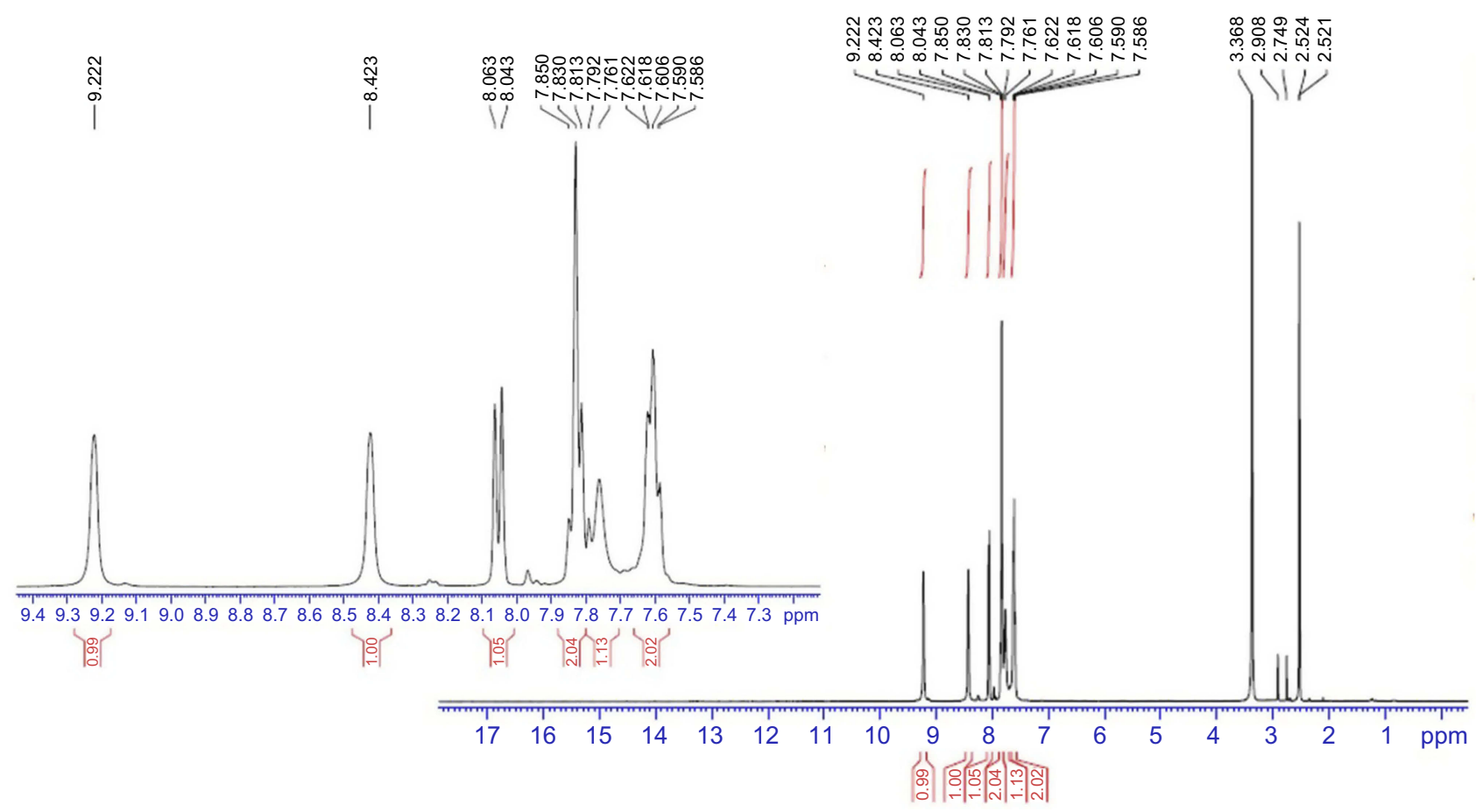

Figure 2 'HNMR spectrum of compound la in DMSO.

Table I Structures and properties of synthetic compounds

\begin{tabular}{|l|l|l|l|l|l|l|l|l|l|}
\hline No. & $\lambda_{\max }(\mathbf{n m})$ & MP ${ }^{\circ} \mathbf{C}$ & $\mathbf{M W}(\mathbf{g} / \mathbf{m o l})$ & $\begin{array}{l}\text { Molecular } \\
\text { formula }\end{array}$ & No. & $\lambda_{\text {max }}(\mathbf{n m})$ & MP ${ }^{\circ} \mathbf{C}$ & MW (g/mol) & $\begin{array}{l}\text { Molecular } \\
\text { formula }\end{array}$ \\
\hline Ia & 402 & $30 \mathrm{I}-303$ & 293.67 & $\mathrm{C}_{10} \mathrm{H}_{8} \mathrm{ClN}_{7} \mathrm{O}_{2}$ & $2 \mathrm{a}$ & 394 & $284-286$ & 286.29 & $\mathrm{C}_{12} \mathrm{H}_{14} \mathrm{~N}_{8} \mathrm{O}$ \\
Ib & 423 & $305-307$ & 293.67 & $\mathrm{C}_{10} \mathrm{H}_{8} \mathrm{ClN}_{7} \mathrm{O}_{2}$ & $2 \mathrm{~b}$ & 423 & $250-252$ & 243.27 & $\mathrm{C}_{11} \mathrm{H}_{13} \mathrm{~N}_{7}$ \\
Ic & 456 & $234-236$ & 262.70 & $\mathrm{C}_{11} \mathrm{H}_{11} \mathrm{ClN}_{6}$ & $2 \mathrm{c}$ & 446 & $307-309$ & 274.24 & $\mathrm{C}_{10} \mathrm{H}_{10} \mathrm{~N}_{8} \mathrm{O}_{2}$ \\
Id & 402 & $286-288$ & 305.7 & $\mathrm{C}_{12} \mathrm{H}_{14} \mathrm{ClN}_{7} \mathrm{O}$ & $2 \mathrm{~d}$ & 384 & $278-280$ & 259.27 & $\mathrm{C}_{11} \mathrm{H}_{13} \mathrm{~N}_{7} \mathrm{O}$ \\
le & 389 & $270-272$ & 287.70 & $\mathrm{C}_{11} \mathrm{H}_{11} \mathrm{ClN}_{6} \mathrm{O}$ & $2 \mathrm{e}$ & 402 & $322-324$ & 274.24 & $\mathrm{C}_{10} \mathrm{H}_{10} \mathrm{~N}_{8} \mathrm{O}$ \\
\hline
\end{tabular}

Abbreviations: MP, melting point; MW, molecular weight.

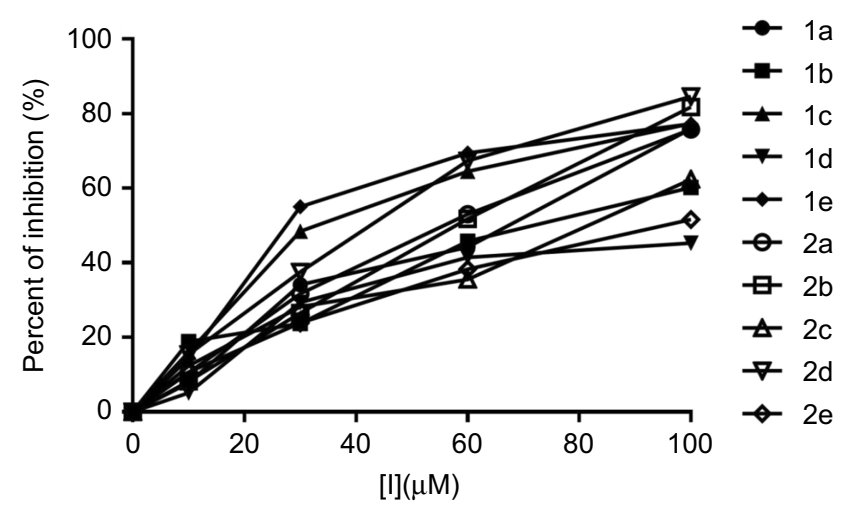

Figure 3 Percent inhibition curve for oxidation of L-DOPA catalyzed by mushroom tyrosinase at increasing concentrations of synthetic pyrimidine derivatives. Inhibitory activity of all synthetic compounds at $30 \mu \mathrm{M}$ is $23.72-55.08 \%$.

Lineweaver-Burk plots showed that all synthetic compounds were a noncompetitive inhibitor of the mushroom tyrosinase (Figure 6).

\section{Docking}

The binding of (1d) to tyrosinase (2Y9W) was computerized by molecular docking. The results of docking were well clustered around the conformer with the best score. According to Figure 7, the results of docking showed that hydrophobic interactions and polar-polar interaction between N3 of the ligand and carbonyl group of Lys5 play a major role in the binding of $1 \mathrm{~d}$ to tyrosinase. Based on the results of the modeling, the dominant interaction is hydrophobic.

\section{Discussion}

Tyrosinase is a rate-limiting monooxygenase enzyme in the process of melanin production. ${ }^{2,5}$ Increasing the activity of this enzyme causes excessive production of melanin and, as a result, hyperpigmentation problems such as melasma and skin spots may occur. ${ }^{4,6}$ Therefore, the discovery 


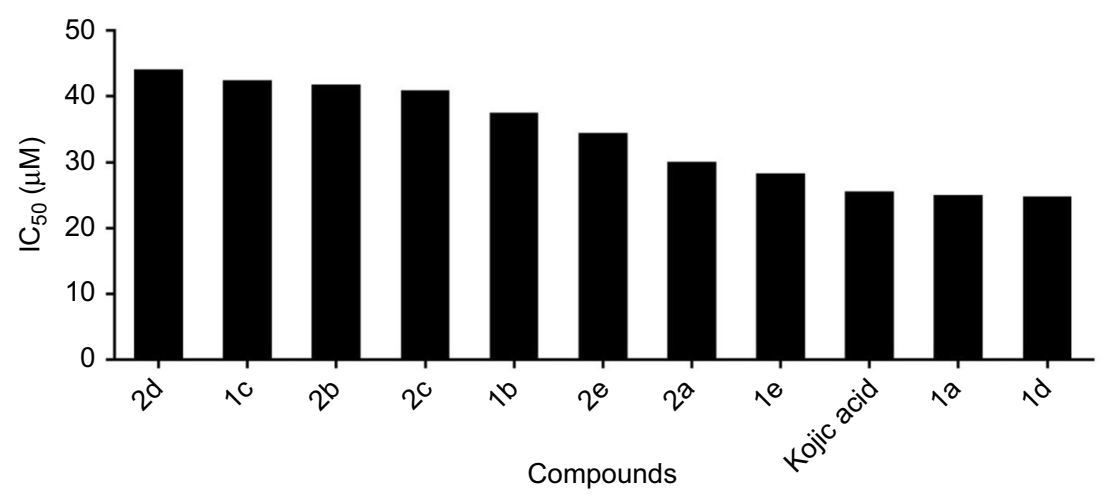

Figure 4 The $\mathrm{IC}_{50}(\mu \mathrm{M})$ values of synthetic compounds against mushroom tyrosinase. L-DOPA was used as substrate and concentrations of synthetic compounds were 10 , $30,60,100 \mu \mathrm{M}$. Absorbance of the reaction was taken at $490 \mathrm{~nm}$. $\left(\left|C_{50}: 2 d>\right| c>2 b>2 c>|b>2 e>2 a>| e>\right.$ kojic acid $\left.>|a>| d\right)$.

Table 2 The kinetic constants and inhibition constants of all synthetic compounds on mushroom tyrosinase

\begin{tabular}{|l|l|l|l|l|l|l|l|}
\hline Compounds & Vmax & Km & $\alpha \mathbf{K i}$ & $\mathbf{K i}$ & Alpha( $\boldsymbol{\alpha})$ & IC $_{\mathbf{5 0}}(\boldsymbol{\mu} \mathbf{M})$ & Inhibition type \\
\hline Control & 125.58 & 0.41 & & & & & \\
Ia & 21.15 & 0.63 & 6.079 & 3.601 & 1.68 & 24.68 & \\
Ib & 24.06 & 0.43 & $7.1 I$ & 6.559 & 1.08 & 37.19 I & Noncompetitive \\
Ic & 24.78 & 0.48 & 7.378 & 5.871 & 1.25 & 42.04 & Noncompetitive \\
Id & 25.01 & 0.39 & 7.464 & 7.837 & 0.95 & 24.4 & Noncompetitive \\
Ie & 23.36 & 0.39 & 6.857 & 7.05 & 0.97 & 28.01 & Noncompetitive \\
$\mathbf{2 a}$ & 21.88 & 0.496 & 6.33 & 4.98 & 1.27 & 29.77 & Noncompetitive \\
$\mathbf{2 b}$ & 19.64 & 0.62 & 5.56 & 3.4 & 1.63 & 41.4 & Noncompetitive \\
$\mathbf{2 c}$ & 23.95 & 0.57 & 7.07 & 4.62 & 1.52 & 40.62 & Noncompetitive \\
$\mathbf{2 d}$ & 22.41 & 0.35 & 6.51 & 7.63 & 0.85 & 43.8 & Noncompetitive \\
$\mathbf{2 e}$ & 23.1 & 0.46 & 6.76 & 5.66 & 1.19 & 34.06 & Noncompetitive \\
\hline
\end{tabular}

\section{A}
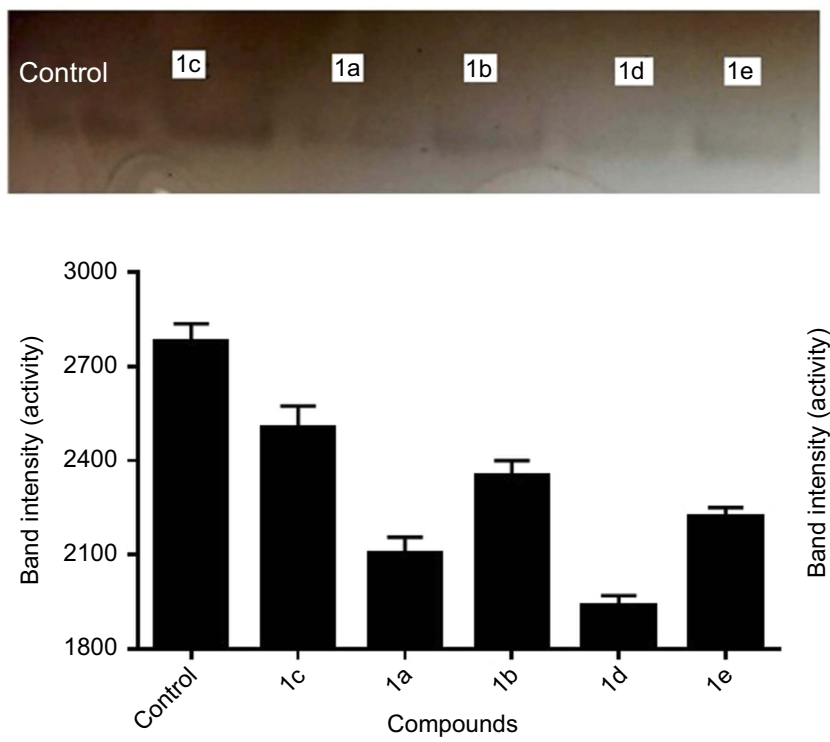

B

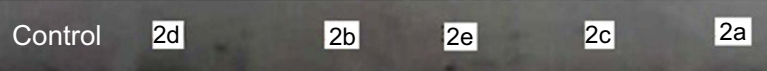

4-chloropyrimidine and (B) based on 2,4,6-triaminopyrimidine. (A: $|d>| a>|e>| b>\mid c)(B: 2 a>2 e>2 c>2 b>2 d)$

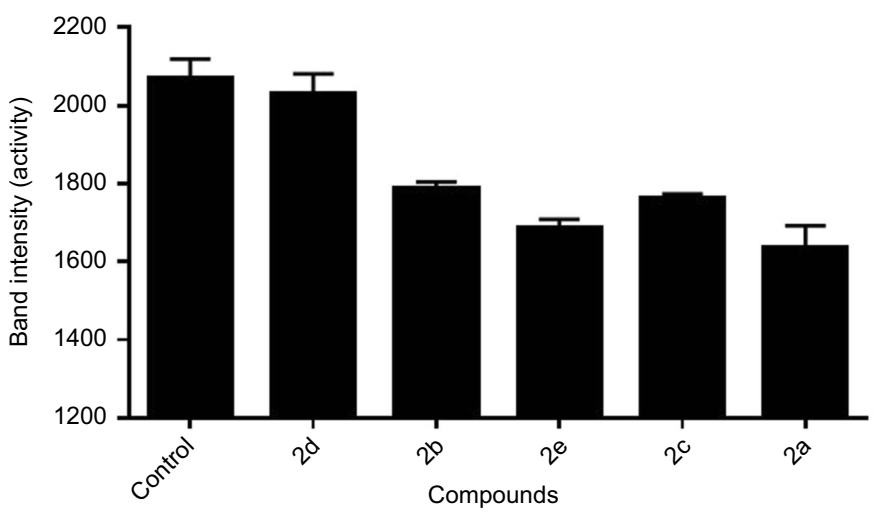

Figure 5 The effect of the synthetized compounds (Ia-e and 2a-e) on the enzyme activity estimated by zymography using L-DOPA staining (A) based on 2,6-diamino- 


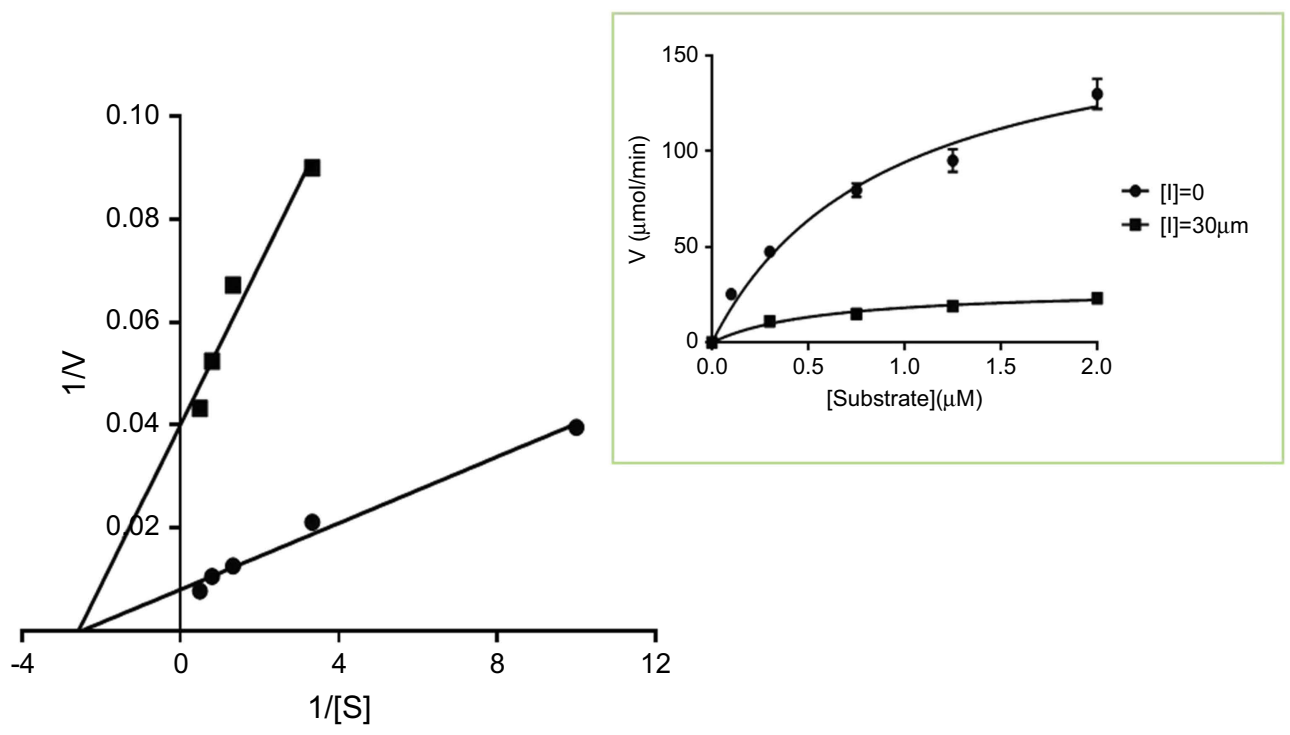

Figure 6 Michaelis-Menten and Lineweaver-Burk plots of the enzyme inhibition by the compound Id.

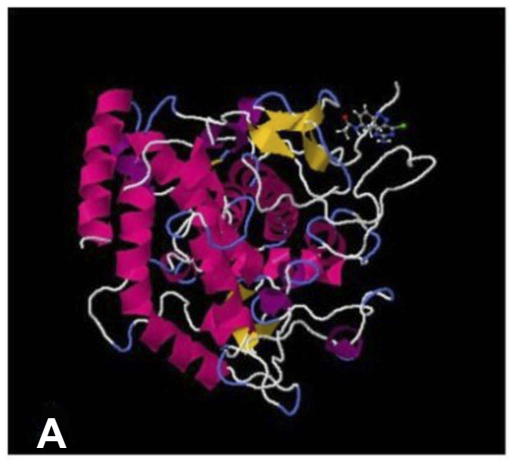

\begin{tabular}{|c|c|c|c|c|}
\hline Show & Cluster & Element & $\begin{array}{l}\text { FullFitness } \\
(\mathrm{kcal} / \mathrm{mol})\end{array}$ & $\begin{array}{l}\text { Estimatec } \\
\Delta G \\
(\mathrm{kcal} / \mathrm{mol}\end{array}$ \\
\hline • & 0 & 0 & -2198.37 & -8.64 \\
\hline 0 & 0 & 1 & -2198.37 & -8.64 \\
\hline 0 & 0 & 2 & -2198.37 & -8.64 \\
\hline 。 & 0 & 3 & -2198.25 & -8.65 \\
\hline 。 & 0 & 4 & -2198.25 & \\
\hline 0 & 0 & 5 & -2197.03 & -8.58 \\
\hline 0 & 0 & 6 & -2197.03 & -8.58 \\
\hline 0 & 0 & 7 & -2197.03 & -8.58 \\
\hline 0 & 1 & 0 & -2194.94 & -8.31 \\
\hline 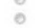 & 1 & 1 & -2194.94 & -8.31 \\
\hline 0 & 1 & 2 & -2194.94 & -8.31 \\
\hline 0 & 1 & 3 & -2194.94 & -8.31 \\
\hline 0 & 1 & 4 & -2194.76 & -8.33 \\
\hline 0 & 1 & 5 & -2194.28 & -8.13 \\
\hline 。 & 1 & 6 & -2194.28 & -8.13 \\
\hline 0 & 1 & 7 & -2194.28 & -8.13 \\
\hline 0 & 1 & 8 & -2183.83 & -7.77 \\
\hline 0 & 1 & 9 & -2183.83 & -7.77 \\
\hline 8 & 1 & 10 & -2183.54 & -7.79 \\
\hline & 1 & 11 & -2183.54 & -7.79 \\
\hline
\end{tabular}
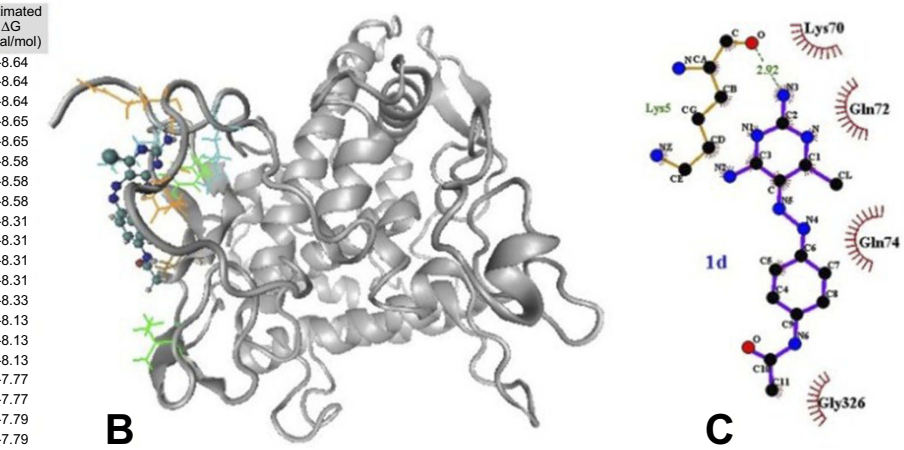

Figure 7 (A) Full fitness $(\mathrm{kcal} / \mathrm{mol})$ and estimated $\Delta \mathrm{G}(\mathrm{kcal} / \mathrm{mol}) ;(\mathbf{B}) 3 \mathrm{D}$ secondary structure of tyrosinase that shows the position of Id at the protein. The important interacting residues are shown by colored lines and Id by CPK drawing method; (C) a LigPlot diagram of the interaction between tyrosinase and Id. Hydrophobic interaction plays a major role in the binding.

and synthesis of safe and effective inhibitors for treating and preventing skin disorders are very important in the medicinal and cosmetic industries. ${ }^{2,27}$ On the other hand, this enzyme plays an important role in physiological processes in insects, including wound healing, sclerotization, and defensive encapsulation. Thus, its inhibitors could be useful as insecticides in the agricultural research activities. $^{10,11}$ Tyrosinase is also responsible for the undesirable browning of fruits and vegetables during storage, which reduces the nutritional and commercial value of the products. ${ }^{8,9}$ Synthesis and detection of effective, harmless and affordable inhibitors is desirable in order to minimize these problems. Over recent years, there have been many studies of screening, discovery, design, and synthesis of novel tyrosinase inhibitors. Pyrimidine derivatives are active heterocyclic compounds with two nitrogen atoms in the ring and have attracted much attention in medicinal chemistry and pharmacology. ${ }^{15,16}$ They have been shown to have anticancer, antiviral, anti-inflammatory, antibacterial and antiparkinson properties. ${ }^{15}$ Considering the reports on the tyrosinase inhibition ability of aromatic amines and anilines, we were encouraged to synthesize some new derivatives based on pyrimidine and aniline derivatives. ${ }^{17}$ In this study, we synthesized and characterized ten novel azo-dyes including bioactive pyrimidine moiety and aniline derivatives. Their inhibitory activities against mushroom tyrosinase were then evaluated. Tyrosinase inhibition assay was carried out with L-DOPA as substrate and kojic acid as reference inhibitor. All synthetic compounds (1a-e and 2a-e) were able to inhibit mushroom tyrosinase activity in a concentration-dependent manner, as shown in Figure 3. The data revealed that compounds with 
a Cl-halide group in the $\mathrm{R}$ position have more inhibitory activity than the compounds with an $\mathrm{NH}_{2}$ group in the $\mathrm{R}$ position. The $1 \mathrm{~d}\left(\mathrm{IC}_{50}=24.45 \mu \mathrm{M}\right)$ and $1 \mathrm{a}\left(\mathrm{IC}_{50}=24.68\right.$ $\mu \mathrm{M}$ ) compounds, possessing acetamide and $\mathrm{NO}_{2}$ groups at position $\mathrm{X}$, respectively, and with $\mathrm{Cl}$ at position $\mathrm{R}$, are more potent inhibitors of mushroom tyrosinase than the other synthesized compounds and $\mathrm{IC}_{50}$ values are slightly better than kojic acid $\left(\mathrm{IC}_{50}=25.24 \mu \mathrm{M}\right)$, the reference tyrosinase inhibitor. The mechanisms of inhibition of mushroom tyrosinase by all synthetic compounds were further investigated by steady-state kinetic analysis. Inhibition data were then determined using LineweaverBurk double reciprocal plots. The outcome of compounds showed that the $1 / \mathrm{V}$ vs $1 /[\mathrm{S}]$ plot gave two straight lines with different slopes, but with one intersection on the horizontal axis, indicating that the values of Vmax decrease without changing the values of $\mathrm{Km}$ when the concentration of these compounds increased. These data suggest that of all synthetic compounds function as noncompetitive inhibitors of tyrosinase (Table 2), hence all synthetic compounds bound both the free enzyme molecule and enzyme-substrate complex. Liu et $\mathrm{al}^{28}$ synthesized several compounds on the basis of thiourea containing $\mathrm{NH}$ group in the ring and evaluated their inhibitory potencies on mushroom tyrosinase. According to their kinetic results, the thiouracil and methylthiouracil synthesized compounds with $\mathrm{IC}_{50}=128$ and $142 \mu \mathrm{M}$, respectively, assigned as noncompetitive inhibitors. ${ }^{28}$ The SAR studies have shown that inhibitory activity of thiourea on tyrosinase enzyme activity must be derived from nitrogen and sulfur atoms. For these two compounds, it was observed that adding a methyl group in the meta position on the ring could reduce the inhibitory effect of the methylthiouracil compound. ${ }^{28}$ According to these results, in the present study, the effect of an NH group in the pyrimidine ring of synthesized compounds was investigated on the potency of inhibition. By comparing the results of the present study with Liu et al it was found that the presence of a methyl group decreases the inhibitory effect of synthetic compounds ( $2 \mathrm{~b}$ and $1 \mathrm{c}) .{ }^{28}$ Also, Bae et $\mathrm{al}^{17}$ reported a series of azo-resveratrol and azooxyresveratrol compounds, containing an azo group in their structure. Among the synthesized compounds, 13b $(\mathrm{R} 1=\mathrm{R} 2=\mathrm{OH}, \mathrm{R} 4=\mathrm{OH}, \mathrm{R} 3=\mathrm{R} 5=\mathrm{H}$; = R6 = OMe $)$ exhibited high tyrosinase inhibitory activity, with an $\mathrm{IC}_{50}$ value of $36.28 \mu \mathrm{M}^{29}$ Therefore, in the present study, all compounds synthesized from base compounds TAP and DATP with 2-nitroaniline, paranitroaniline, paramethyl aniline, paramethoxyaniline and para-aminoacetanilide containing the azo group. Considering the effect of ortho and para position on the benzene ring of synthetic compounds, it was found that $2 \mathrm{e}\left(\mathrm{IC}_{50}=34.06\right)$ with a nitro group at position ortho had a more potent inhibitory effect on tyrosinase activity than $2 \mathrm{c}\left(\mathrm{IC}_{50}=40.62\right)$ with a nitro group at the para position. Bae et al synthesized methoxyaniline derivatives and evaluated as a tyrosinase inhibitor. $^{17}$ The theoretical studies conducted in this study identified the interaction of synthetic compounds with the key amino acids of tyrosinase (PDB $=2 \mathrm{Y} 9 \mathrm{~W})$.

\section{Acknowledgment}

The authors thank the Research Council of the University of Guilan for the financial support of this study.

\section{Author contributions}

All authors contributed to data analysis, drafting or revising the article, gave final approval of the version to be published, and agree to be accountable for all aspects of the work.

\section{Disclosure}

The authors report no conflicts of interest in this work.

\section{References}

1. Rezaei M, Mohammadi HT, Mahdavi A, Shourian M, Ghafouri H. Evaluation of thiazolidinone derivatives as a new class of mushroom tyrosinase inhibitors. Int J Biol Macromol. 2018;108:205-213. doi:10.1016/j.ijbiomac.2017.11.147

2. Yun HY, Do Hyun Kim SS, Ullah S, et al. Design, synthesis, and anti-melanogenic effects of (E)-2-benzoyl-3-(substituted phenyl) acrylonitriles. Drug Des Devel Ther. 2015;9:4259.

3. Ramsden CA, Riley PA. Tyrosinase: the four oxidation states of the active site and their relevance to enzymatic activation, oxidation and inactivation. Bioorg Med Chem. 2014;22(8):2388-2395. doi:10.1016/j. bmc.2014.02.048

4. Thanigaimalai P, Le Hoang TA, Lee K-C, et al. Structural requirement (s) of $\mathrm{N}$-phenylthioureas and benzaldehyde thiosemicarbazones as inhibitors of melanogenesis in melanoma B 16 cells. Bioorg Med Chem Lett. 2010;20(9):2991-2993. doi:10.1016/j.bmcl.2010.02.067

5. Al-Amin M, Cao J, Naeem M, et al. Increased therapeutic efficacy of a newly synthesized tyrosinase inhibitor by solid lipid nanoparticles in the topical treatment of hyperpigmentation. Drug Des Devel Ther. 2016;10:3947. doi:10.2147/DDDT.S123759

6. Abbas Q, Ashraf Z, Hassan M, et al. Development of highly potent melanogenesis inhibitor by in vitro, in vivo and computational studies. Drug Des Devel Ther. 2017;11:2029. doi:10.2147/DDDT.S137550

7. Harris Z, Donovan MG, Branco GM, Limesand KH, Burd R. Quercetin as an emerging anti-melanoma agent: a four-focus area therapeutic development strategy. Front Nutr. 2016;3:48. doi: $10.3389 /$ fnut.2016.00048

8. Loizzo M, Tundis R, Menichini F. Natural and synthetic tyrosinase inhibitors as antibrowning agents: an update. Compr Rev Food Sci Food Saf. 2012;11(4):378-398. doi:10.1111/j.1541-4337.2012.00191.x 
9. Do Hyun Kim SJK, Ullah S, Yun HY, Chun P, Moon HR. Design, synthesis, and antimelanogenic effects of (2-substituted phenyl-1, 3-dithiolan-4-yl) methanol derivatives. Drug Des Devel Ther. 2017;11:827. doi:10.2147/DDDT.S131538

10. Sugumaran M, Barek H. Critical analysis of the melanogenic pathway in insects and higher animals. Int J Mol Sci. 2016;17(10):1753. doi:10.3390/ijms 17101753

11. Gorman MJ, Arakane Y. Tyrosine hydroxylase is required for cuticle sclerotization and pigmentation in Tribolium castaneum. Insect Biochem Mol Biol. 2010;40(3):267-273. doi:10.1016/j.ibmb.2010.01.004

12. Battaini G, Monzani E, Casella L, Santagostini L, Pagliarin R. Inhibition of the catecholase activity of biomimetic dinuclear copper complexes by kojic acid. JBIC J Bio Inorg Chemistry. 2000;5(2):262-268.

13. Zhu Y-J, Zhou H-T, Hu Y-H, et al. Antityrosinase and antimicrobial activities of 2-phenylethanol, 2-phenylacetaldehyde and 2-phenylacetic acid. Food Chem. 2011;124(1):298-302. doi:10.1016/j.foodchem. 2010.06.036

14. GąSowska B, Kafarski P, Wojtasek H. Interaction of mushroom tyrosinase with aromatic amines, o-diamines and o-aminophenols. Biochim Et Biophys Acta (Bba)-Gen Subj. 2004;1673(3):170-177. doi:10.1016/j.bbagen.2004.04.013

15. Bhat AR. Biological activity of pyrimidine derivativies: a review. Org Med Chem IJ. 2017;2(2):1-4.

16. Dansena H, Dhongade H, Chandrakar K. Pharmacological potentials of pyrimidine derivative: a review. Asian J Pharm Clin Res. 2015;8 (4):171-177.

17. Bae SJ, Ha YM, Park YJ, et al. Design, synthesis, and evaluation of (E)-N-substituted benzylidene-aniline derivatives as tyrosinase inhibitors. Eur J Med Chem. 2012;57:383-390. doi:10.1016/j. ejmech.2012.09.026

18. Mohammadi A, Ghafoori H, Ghalami-Choobar B, Rohinejad R. Synthesis, solvatochromic properties and biological evaluation of some novel azo-hydrazone tautomeric dyes. $J$ Mol Liq. 2014;198:44-50. doi:10.1016/j.molliq.2014.07.005

19. Jimenez-Cervantes C, Valverde P, García-Borrón JC, Solano F, Lozano JA. Improved tyrosinase activity stains in polyacrylamide electrophoresis gels. Pigm Cell Res. 1993;6(6):394-399.
20. Ismaya WT, Rozeboom HJ, Weijn A, et al. Crystal structure of Agaricus bisporus mushroom tyrosinase: identity of the tetramer subunits and interaction with tropolone. Biochemistry. 2011;50 (24):5477-5486. doi:10.1021/bi200395t

21. Word JM, Lovell SC, Richardson JS, Richardson DC. Asparagine and glutamine: using hydrogen atom contacts in the choice of side-chain amide orientation. J Mol Biol. 1999;285(4):1735-1747. doi:10.1006/ jmbi.1998.2401

22. Trott O, Olson AJ. AutoDock Vina: improving the speed and accuracy of docking with a new scoring function, efficient optimization, and multithreading. J Comput Chem. 2010;31(2):455-461. doi:10.1002/ jec. 21334

23. Sanner MF. Python: a programming language for software integration and development. J Mol Graph Model. 1999;17(1):57-61.

24. Coleman WF, Arumainayagam CR. HyperChem 5 (By Hypercube, Inc.). J Chem Educ. 1998;75:4. https://doi.org/10.1021/ed075p416

25. Grosdidier A, Zoete V, Michielin O. EADock: docking of small molecules into protein active sites with a multiobjective evolutionary optimization. Proteins. 2007;67(4):1010-1025. doi:10.1002/ prot. 21367

26. Wallace AC, Laskowski RA, Thornton JM. LIGPLOT: a program to generate schematic diagrams of protein-ligand interactions. Protein Eng Des Sel. 1995;8(2):127-134. doi:10.1093/protein/8.2.127

27. Parvez S, Kang M, Chung HS, Bae H. Naturally occurring tyrosinase inhibitors: mechanism and applications in skin health, cosmetics and agriculture industries. Phytother Res. 2007;21(9):805-816. doi:10.1002/ptr.2184

28. Liu P, Shu C, Liu L, Huang Q, Peng Y. Design and synthesis of thiourea derivatives with sulfur-containing heterocyclic scaffolds as potential tyrosinase inhibitors. Bioorg Med Chem. 2016;24 (8):1866-1871. doi:10.1016/j.bmc.2016.03.013

29. Pillaiyar T, Manickam M, Namasivayam V. Skin whitening agents: medicinal chemistry perspective of tyrosinase inhibitors. J Enzyme Inhib Med Chem. 2017;32(1):403-425. doi:10.1080/14756366. 2016.1256882
Drug Design, Development and Therapy

\section{Publish your work in this journal}

Drug Design, Development and Therapy is an international, peerreviewed open-access journal that spans the spectrum of drug design and development through to clinical applications. Clinical outcomes, patient safety, and programs for the development and effective, safe, and sustained use of medicines are a feature of the journal, which has also

\section{Dovepress}

been accepted for indexing on PubMed Central. The manuscrip management system is completely online and includes a very quick and fair peer-review system, which is all easy to use. Visit http://www. dovepress.com/testimonials.php to read real quotes from published authors. 